\title{
Development of a Polymer Endovascular Prosthesis and its Implantation in Porcine Arteries
}

\author{
WILLEM J. van DER GIESSEN, M.D., CORNELIS J. SLAGER, M.Sc., HELEEN M.M. vaN \\ BEUSEKOM, M.Sc., DORETTE S. van INGEN SCHENAU, RUUD A. HUIJTS, Ph.D.,* \\ JOHAN C. SCHUURBIERS, B.Sc., WILLEM J. DE KLEIN, PH.D., ${ }^{* *}$ PATRICK W. SERRUYS, \\ M.D., and PIETER D. VERDOUW, PH.D.
}

From the Department of Cardiology, Thoraxcenter, Erasmus University Rotterdam, Rotterdam, *Akzo Research

Laboratories and ${ }^{* *}$ Akzo Fibres B.V., Arnhem, The Netherlands

\begin{abstract}
A polyethylene-terephthalate braided mesh stent has been developed for application in the (coronary) arterial tree. In vitro measurements showed that the radial pressure delivered by this device was in the same range as that of a stainless steel stent. Hysteresis-like behavior, however, occurred after constraining the polyester stent for a period of only 15 minutes on a delivery system for percutaneous implantation. This implies that the polymer stent must be mounted on this delivery system immediately before the placement procedure, and that either a diameter in the unconstrained condition must be selected, which is considerably larger than the diameter of the target vessel, or stent expansion has to be enhanced by balloon expansion. Taking into account the results obtained during the in vitro studies, we investigated the angiographic patency and histologic features after implantation of this polyester stent in peripheral arteries of pigs. In four animals eight stents were placed. Except for heparin during the implantation procedure only, antithrombotic or antiplatelet drugs were not administered. After 4 weeks repeat angiography was performed. Angiography revealed that five of the six correctly placed stents were patent. At autopsy, two additional patent stents proved to be located in the aortic bifurcation, probably due to failure of the delivery system. Quantitative assessment showed that the mean luminal diameters at the site of stent placement were $3.3 \pm 0.2 \mathrm{~mm}$ before, $3.2 \pm 0.2 \mathrm{~mm}$ immediately after, and $3.1 \pm 0.3 \mathrm{~mm}$ at 4 weeks after implantation. Histology demonstrated an inflammatory reaction of variable severity around the stent fibers. Quantitative histologic measurements showed that the thickness of the neointima was $114 \pm 38 \mu \mathrm{m}$ after 4 weeks. In conclusion, polyester stents can be constructed with mechanical properties similar to stainless steel stents. Hysteresis-like behavior of polyester stents, however, influences the selection of the nominal stent diameter as well as the forces exerted to the vessel wall. After implantation in porcine peripheral arteries, five of six correctly placed stents were patent at 4 weeks. The extent of neointimal proliferation was similar to that observed after placement of metal stents in swine, despite the presence of a more pronounced inflammatory reaction. (J Interven Cardiol 1992; 5:175-185)
\end{abstract}

\section{Introduction}

Percutaneous transluminal coronary angioplasty (PTCA) is an accepted and increasingly

\footnotetext{
Address for reprints: Willem J. van der Giessen, M.D., Thoraxcenter, Ee 2357, Erasmus University Rotterdam, P.O. Box 1738, 3000 DR Rotterdam, The Netherlands. Fax: (10) 4365192.

Submitted for publication November 15, 1991; accepted for publication January 15, 1992.
}

used treatment for obstructive atherosclerotic coronary artery disease. PTCA has a high initial success rate, ${ }^{1,2}$ except in $2 \%-7 \%$ of cases of acute or subacute occlusion at the site where angioplasty occurs. ${ }^{3-5}$ Pharmacological therapy, except for the administration of aspirin, ${ }^{6-8}$ is ineffective and, although redilatation of an acutely occluded artery can be successful, it is frequently necessary to proceed to emergency coronary bypass surgery. ${ }^{5}$ Late restenosis after successful coronary angioplasty is the second important lim- 
itation of PTCA. ${ }^{9-11}$ Pharmacological prevention of restenosis has also failed. ${ }^{12-14}$

A novel approach for the treatment of acute complications or the prevention of restenosis after PTCA may be the placement of a metallic endovascular prosthesis (stents). ${ }^{15.16}$ Results from uncontrolled clinical studies with stainless steel stents in the coronary circulation indicate, however, that these devices are prone to (sub)acute thrombotic occlusion and, although reduce, do not eliminate the occurrence of restenosis. ${ }^{17-20}$ In animal experiments, coronary stents composed of tantalum proved to be less thrombogenic than stainless steel stents, ${ }^{21}$ but the initial results after implantation of tantalum stents in patients do not show this to be a detectable advantage. ${ }^{22}$ Nonthrombogenic polymers are potentially good candidates to replace metal or to serve as an outer coating on metal devices. In this study, we report on the results obtained with a synthetic polymer stent in vitro and after placement in porcine peripheral arteries.

\section{Methods}

Polymer Stent. The stent developed is a cylindrical braided mesh, constructed of 24 polyester (polyethylene-terephthalate, molecular weight 30.000 ; no antioxidant or plasticiser added) monofilaments of $176 \mu \mathrm{m}$ in diameter (Fig. 1). The fibers at both ends of the stent were thermally fused. This stent can be constrained on a delivery system, consisting of two coaxial catheters (Fig. 2). The diameter of delivery catheter plus stent is $2.8 \mathrm{~mm}$. Withdrawal of the outer catheter will release the stent progressively, which anchors itself against the arterial wall, when the diameter of the stent after release exceeds the vessel diameter. The unconstrained diameter of the stents used in this study was $5.3 \mathrm{~mm}$.

In Vitro Force-Length Measurements. Long segments (>100 $\mathrm{mm}$ ) of stent material were positioned in a force-length (F-L) measurement system. Both extremities of the stent had limited expansile properties, because they were fixed in the system, and, therefore, only the mid-section was used for measuring the F-L relationship. Data were obtained at $20^{\circ} \mathrm{C}$ and at $37^{\circ} \mathrm{C}$.

Using this F-L measurement system, the length of the selected mid-segment of the stent was determined after applying several known forces $(F)$. Knowledge of the length-radius ( $L-r)$ relationship, $\mathrm{L}=f(\mathrm{r})$, and the surface area $(\mathrm{A}=\mathrm{L} .2 \pi . \mathrm{r})$ of this specific cylindric stent construction (Fig.

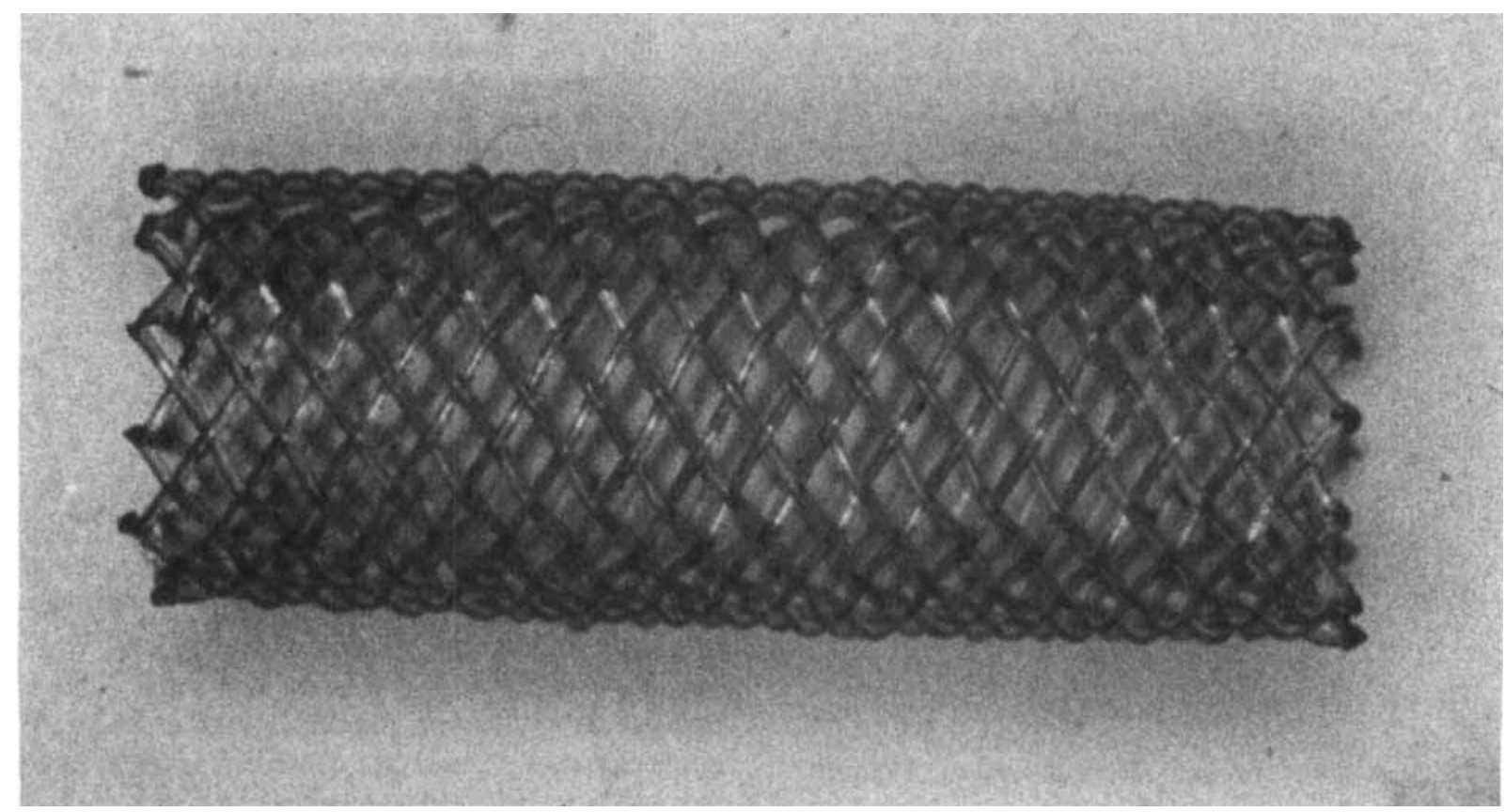

Figure 1. Mesh stent, braided of 24 polyester monofilaments, each $176 \mu \mathrm{m}$ in diameter. The unconstrained diameter of the stent is $5.3 \mathrm{~mm}$, and its length $15 \mathrm{~mm}$. 


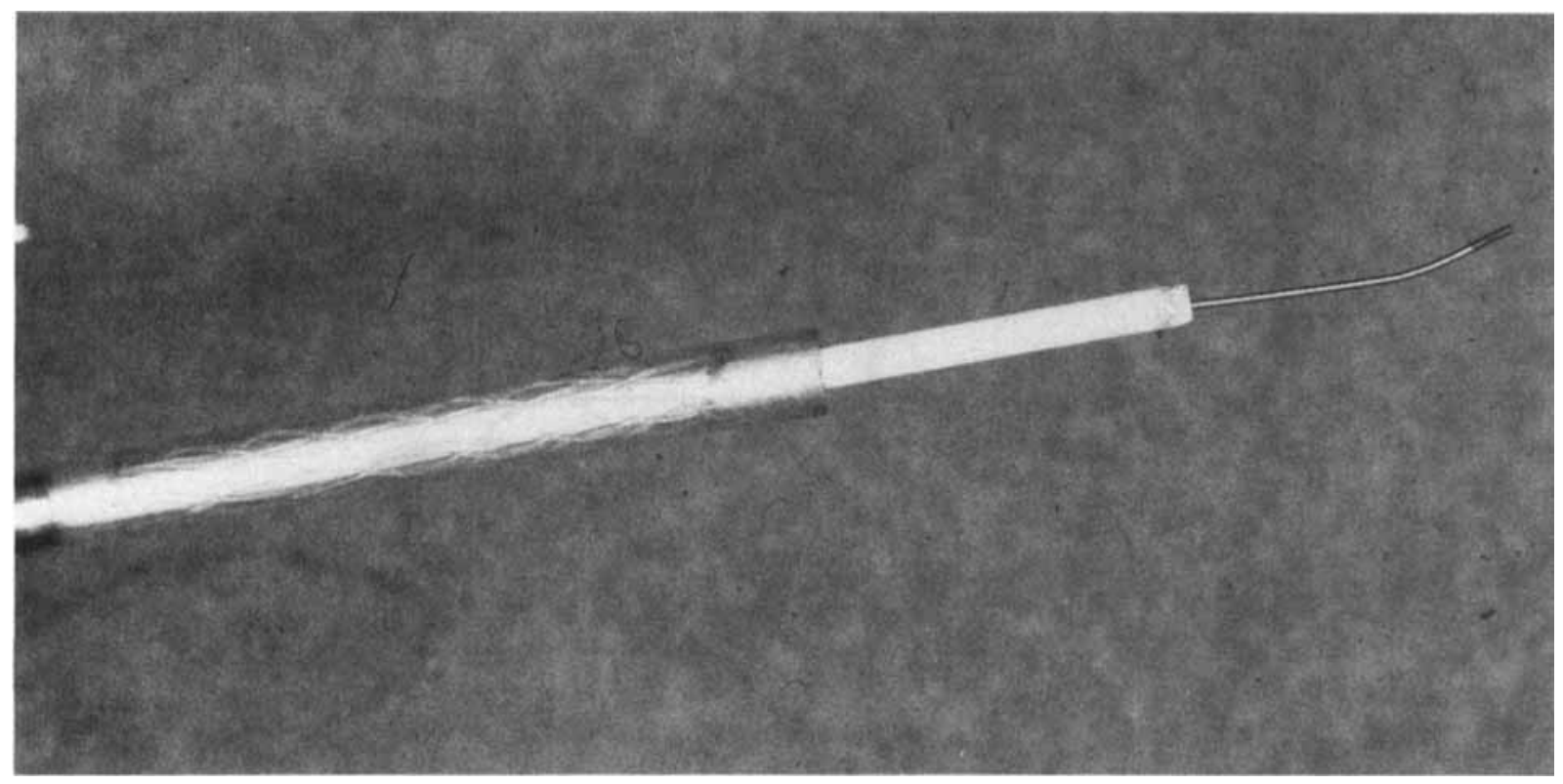

Figure 2. Polyester stent, constrained between the two coaxial catheters of the delivery system. The inner catheter contains a radiopaque, metal ring that forces and as a result of that releases the stent from the outer catheter, at the withdrawal of the latter.

3), allowed the calculation of its radial pressure (P) from the equation: P.A. $\Delta r=-F \cdot \Delta L$, assuming equal work to be delivered by either pressure $\mathrm{P}$ or force $\mathrm{F}$. The application of this formula yields global delivered pressure, assuming a stent with a closed cylindric surface. Correction for the actual fiber-covered area to total stent area allowed calculation of the locally delivered pressure to the wall at the fiber surface. Conversion of $\Delta \mathrm{L}$ to diameter was also calculated using the length-radius relationship.

Results of the polyester stent were compared to those obtained with the stainless steel Wallstent endovascular prosthesis (Medinvent, Lausanne, Switzerland). ${ }^{17}$

Stent Expansion After Release In Vitro. The polyester stent was mounted on the delivery system as described above. After 15 minutes the stents were released and the diameter measured immediaiely and at $1,5,15$, and 30 minutes and again after 15 hours using a stereomicroscope.

The same diameter measurements were obtained for the Wallstent coronary stent.

Animal Preparation. Experiments were performed in four Göttingen minipigs (24-28 kg), and complied to the Guide for the Care and Use of Laboratory Animals by the American Physiologi- cal Society (DHEW publication No. [NIH] $80-23,1980$ ). The protocol was approved by the Committee on Experimental Animals of the Erasmus University. After anesthesia and under sterile conditions an arteriotomy of the left carotid artery was performed and a 9 French introduction sheath was placed, as described previously. ${ }^{21}$ Then 5,000 IU heparin sodium was administered and an 8 French catheter was advanced to the infrarenal abdominal aorta. After measurement of arterial blood pressure and heart rate, and measurement of blood gases and acid-base balance (settings of the ventilator corrected, if necessary), $1 \mathrm{mg}$ of isosorbide dinitrate was administered intraarterially, before angiography of the femoral arteries was performed using iopamidol (Iopamiro $^{R} 360$, Dagra BV, Diemen, The Netherlands) as contrast agent.

Stent Implantation. From the angiograms, and using the diameter of the guiding catheter as a reference, a segment with a diameter of about 3.5 $\mathrm{mm}$ was selected in seven femoral arteries and one carotid artery. Then the stent delivery catheter was advanced over a 0.014-inch steerable guidewire to the site preselected for implantation. After administration of additional 2,500 IU heparin, the stents were placed. 


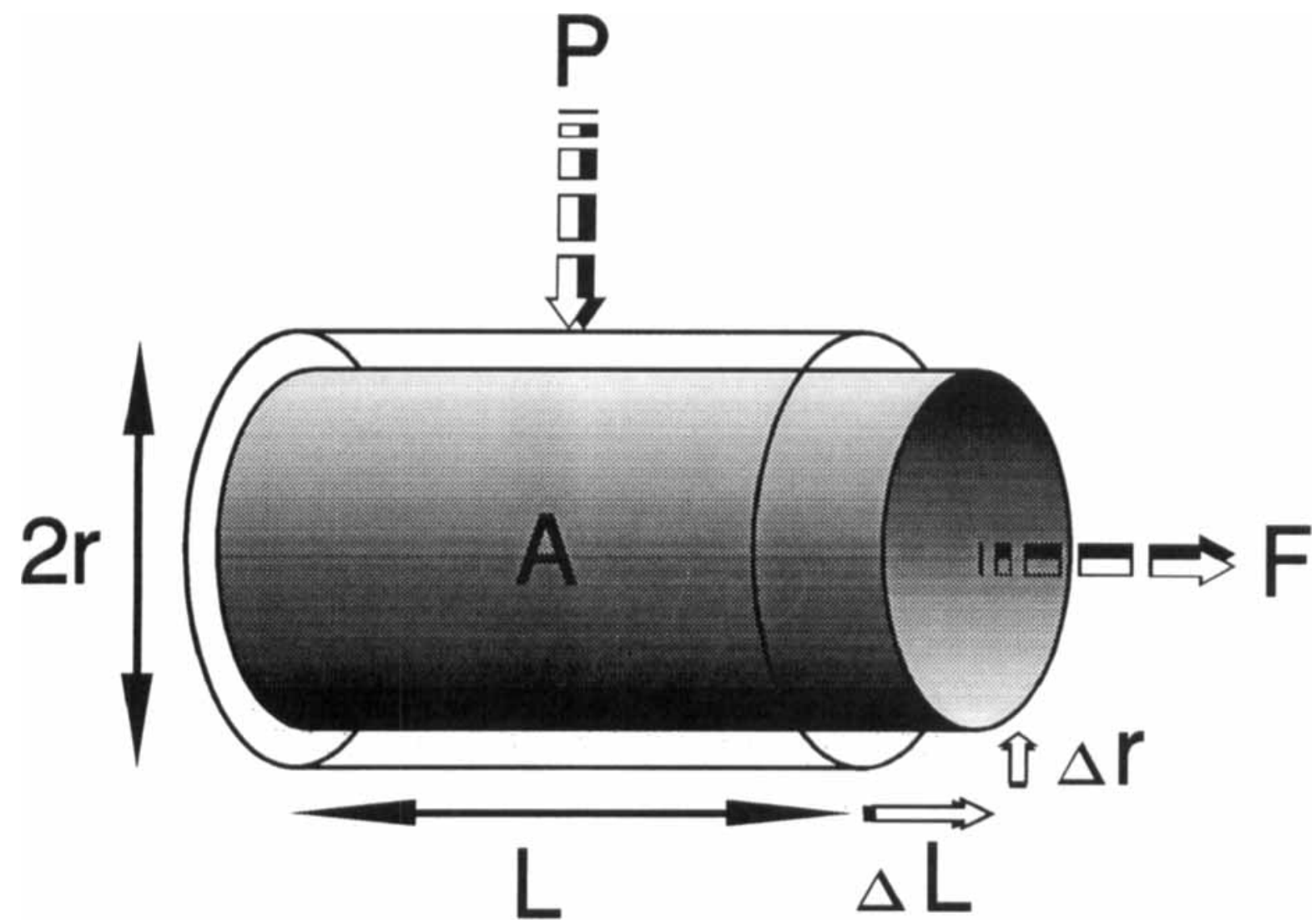

Figure 3. Schematic drawing of two geometric conditions of the stent. The parameters used for the calculation of the pressurediameter relationship are explained in the text.

After repeat angiography of the stented arteries, the introducer sheath was removed, the arteriotomy repaired, and the skin closed in two layers. The animals were allowed to recover from anesthesia. Postprocedure antithrombotic drugs were not administered.

Follow-Up Angiography. The catheterization procedure at 4 weeks follow-up was identical as described above. Angiography was performed in the same projection and using identical settings of the $\mathrm{x}$-ray equipment as during implantation.

Angiographic Analysis. Angiograms (preimplantation, immediately after implantation, and after 4 weeks) were analyzed using the quantitative cardiovascular angiography analysis system (CAAS). ${ }^{23-25}$ Mean luminal diameter at the site of stent placement was measured.

Microscopical Examination. After repeat angiography at 4 weeks, the abdominal aorta was can- nulated and, after administration of a lethal dose of pentobarbital sodium, cross-clamped proximal to the canula. Through the canula $500 \mathrm{~mL}$ of saline followed by $400 \mathrm{~mL}$ of buffered $4 \%$ paraformaldehyde was infused. The femoral arteries were dissected free and the stented segments and adjacent unstented segments were placed in $4 \%$ paraformaldehyde or $4 \%$ paraformaldehyde plus $1 \%$ glutaraldehyde in phosphate buffer $(\mathrm{pH} 7.30)$ for at least $\mathbf{4 8}$ hours in preparation for light and electron microscopy, respectively, as previously described. ${ }^{21.26}$

Qualitative examination was performed for all eight vessels after staining with hematoxylinazophloxin and resorcin-fuchsine as elastin stain using a light microscope (BH2, Olympus, Tokyo, Japan).

For the measurement of the thickness of the various layers of the arterial wall, at least two 


\section{POLYESTER STENTS IN PIGS}

perpendicular resorcin-fuchsine stained sections of the proximal, middle, and distal part of each stented arterial segment were projected on a video screen and the external and internal elastic lamina and the endothelial lining were traced using an integrated image analysis system (IBAS2000 , Kontron, Oberkochen, FRG). ${ }^{27.28}$ The distance between the endothelial lining and the internal elastic lamina was taken as the thickness of the intima. The media was defined as the layer between the internal and external elastic lamina.

Scanning electron microscopy (JSM 25, Jeol Ltd., Tokyo, Japan) was performed on two properly placed stented arteries, using previously described methods. ${ }^{21}$

Statistical Analysis. All quantitative data are expressed as mean \pm SEM. The significance of the changes in the angiographic data were evaluated by analysis of variance (ANOVA) and a two-sample Student's $t$-test. The histologic measurements were analyzed by the two-sample Wilcoxon's

A: global radial pressure of stent

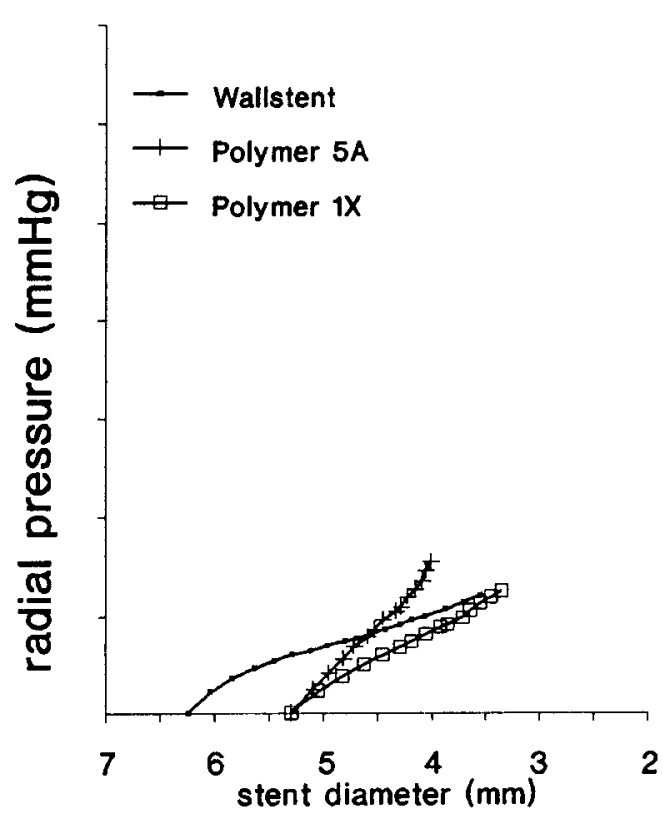

rank sum test. A P value $<0.05$ was considered statistically significant.

\section{Results}

In Vitro Radial Pressure-Diameter Relationship. Figure 4 illustrates that by reducing the diameter of the unconstrained Wallstent from 6.2 to 5.0 $\mathrm{mm}$, a global pressure of approximately $70 \mathrm{mmHg}$ is exerted. Expressing this pressure after correction for the actual fiber surface area, because the stent is not a closed cylinder but an open weave structure, this results in a local pressure at the individual wires of more than $400 \mathrm{mmHg}$. The curves for the polyester stents show increases in radial pressure, after reduction of the diameters from 5.3 to $4.0 \mathrm{~mm}$, similar to those observed with the stainless steel stent. Significant changes in the mechanical behavior of polyester stents can be introduced by modifications in the heat setting

\section{B: radial pressure under stent fibre}

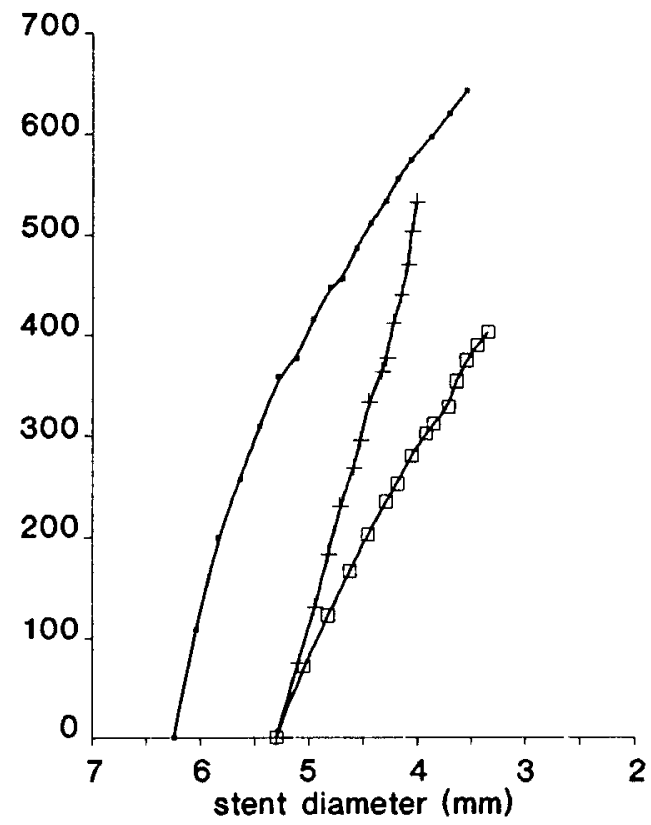

Figure 4. Pressure-diameter relation of stainless steel (Wallstent) and two polymer (polyethylene-terephthalate) stents. Note the steep build up of pressure caused by only minor changes in the diameter of all three stents. Data for the Wallstent prosthesis were published earlier. ${ }^{36}$ Polymer $5 \mathrm{~A}$ : polyester stent heat-setted for 5 minutes at $100^{\circ} \mathrm{C}$ on the nucleus for braiding; Polymer $1 \mathrm{X}$ : polyester stent also heat-setted for 5 minutes at $100^{\circ} \mathrm{C}$, but at lower tension than polymer $5 \mathrm{~A}$. 


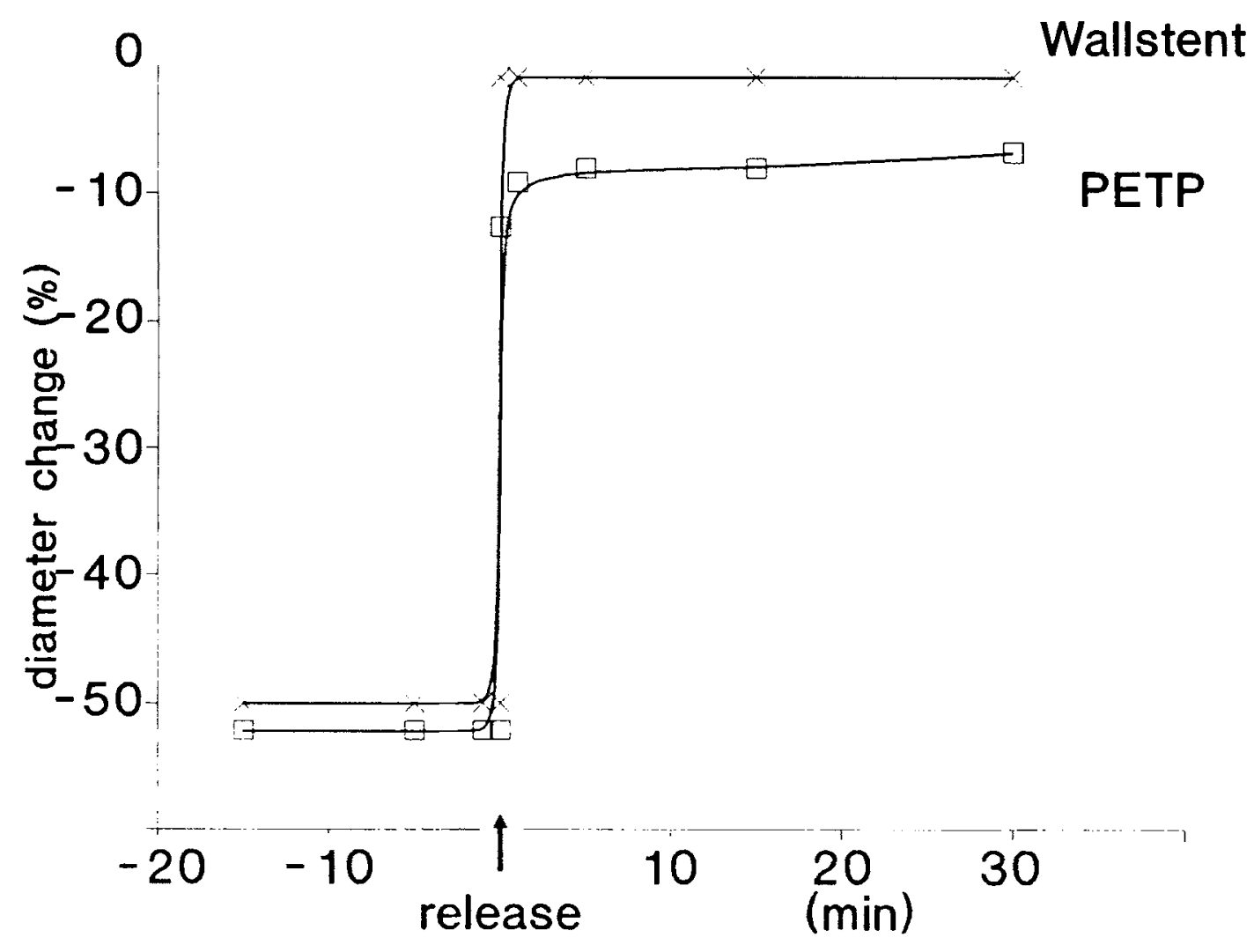

Figure 5. Percentage change in stent diameter from unconstrained diameter $(0 \%)$ of the polyester stent as compared to the Wallstent. Mounting both types of stents on a delivery system reduces their diameter to about $50 \%$. Subsequent release causes the Wallstent to regain its original diameter immediately. The polyester stent does not return to its original diameter within 30 minutes.

process, as shown by the results for the two types of polyester in Figure 4. Measurements at body temperature or at room temperature yielded the same results.

Hysteresis-Like Behavior After Release In Vitro. Unlike the stainless steel Wallstent, the self-expanding polyester stent did not return to its unconstrained diameter after release from the delivery catheter (Fig. 5). At 30 minutes and at 15 hours after release the polyester stent had lost $7 \%$ of its unconstrained diameter. This important finding was taken into account for the selection of the stent diameters for in vivo implantation.

In Vivo Implantation. For all eight stents placement seemed uneventful and easy at the preselected arterial sites. After 4 weeks one stented femoral artery was angiographically occluded. An unexpected finding at autopsy was that in one animal both stents were found patent at the aortic bifurcation, extending into, but not occluding, the origin of both iliac arteries.

Quantitative Angiography. The mean diameter at the site of the stents in the six arteries with correctly placed stents measured, before implantation, $3.3 \pm 0.2 \mathrm{~mm}$ in diameter. After implantation this value was $3.2 \pm 0.2 \mathrm{~mm}$, confirming that the stents did not overstretch the vessels. At 4 weeks the patent arteries measured $3.1 \pm 0.3$ $\mathrm{mm}$, while one stent was found subtotally occluded with a diameter of $0.8 \mathrm{~mm}$. The mean difference between the angiographic values immediately after implantation and after 4 weeks was $0.5 \mathrm{~mm}$ ( $95 \%$ confidence limits: -0.54 and +1.54 $\mathrm{mm}, \mathrm{P}>0.05$ ).

Histology. Macroscopically, the patent stents were covered with a thin, almost transparent, tissue layer without signs of mural thrombosis (Fig. 6). 


\section{POLYESTER STENTS IN PIGS}

Under the stent fibers the media was compressed (Fig. 7), but other abnormalities of the media, such as inflammatory reactions, were not observed.

The histologic appearance of the intima, however, varied considerably. In general, an inflammatory infiltrate surrounded all fibers but while in some vessels only a few layers of macrophages were present, an extensive reaction with polymorphonuclear granulocytes, predominantly eosinophilic granulocytes, lymphocytes, and macrophages were observed in others. Multinucleated giant cells were present next to the polyester filaments in almost all vessels. In addition, inflammatory cells were also observed encapsulating polymer inclusions separated from the fibers in the neointima.

Apart from the inflammatory reaction, the neointima contained abundant neovascularizations.
In one artery, the neointima was almost acellular in a well-defined region above the polyester filaments. At some sites, especially at these acellular neointimal areas, the endothelium was absent.

Quantitative Histologic Measurements. The neointima measured on top of the polymer filaments had a thickness of $114 \pm 38 \mu \mathrm{m}$ and between the fibers $246 \pm 44 \mu \mathrm{m}(\mathrm{n}=5)$. The media under the threads had a thickness of $132 \pm 41 \mu \mathrm{m}$ and between the threads $173 \pm 41 \mu \mathrm{m}(\mathrm{n}=5)$. The difference in thickness of the neointima and the media at the two sites only approximated levels of statistical significance $(P=0.09)$. On average the media under the filaments was compressed by $27 \pm 5 \%(\mathrm{P}=0.07)$ as compared to the media in between the filaments.

Scanning Electron Microscopy. Scanning electron microscopical examination of both studied arteries showed areas of endothelialization at 4

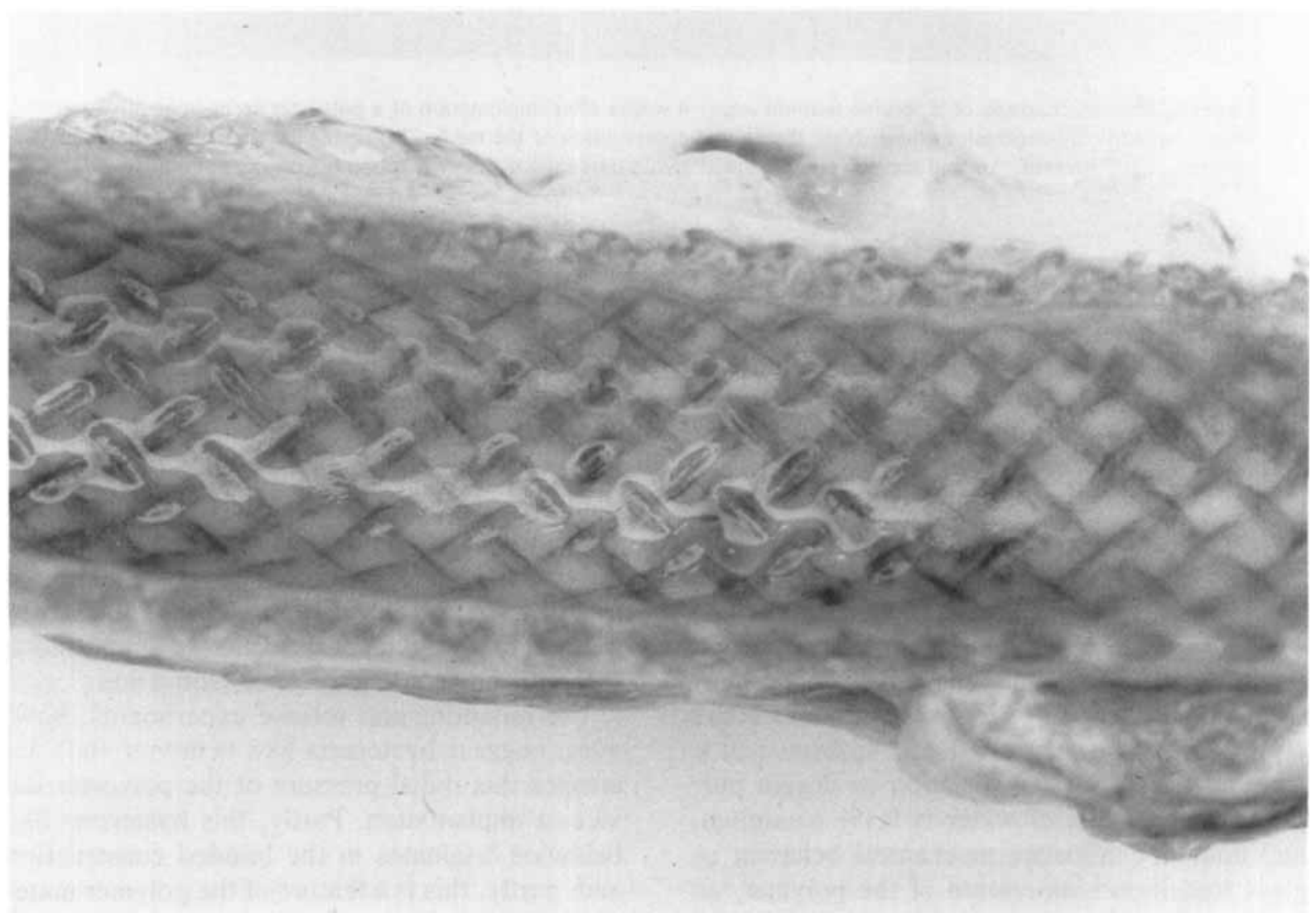

Figure 6. Macroscopic specimen of polyester (PETP) stent 4 weeks after implantation in normal, porcine femoral arteries. 


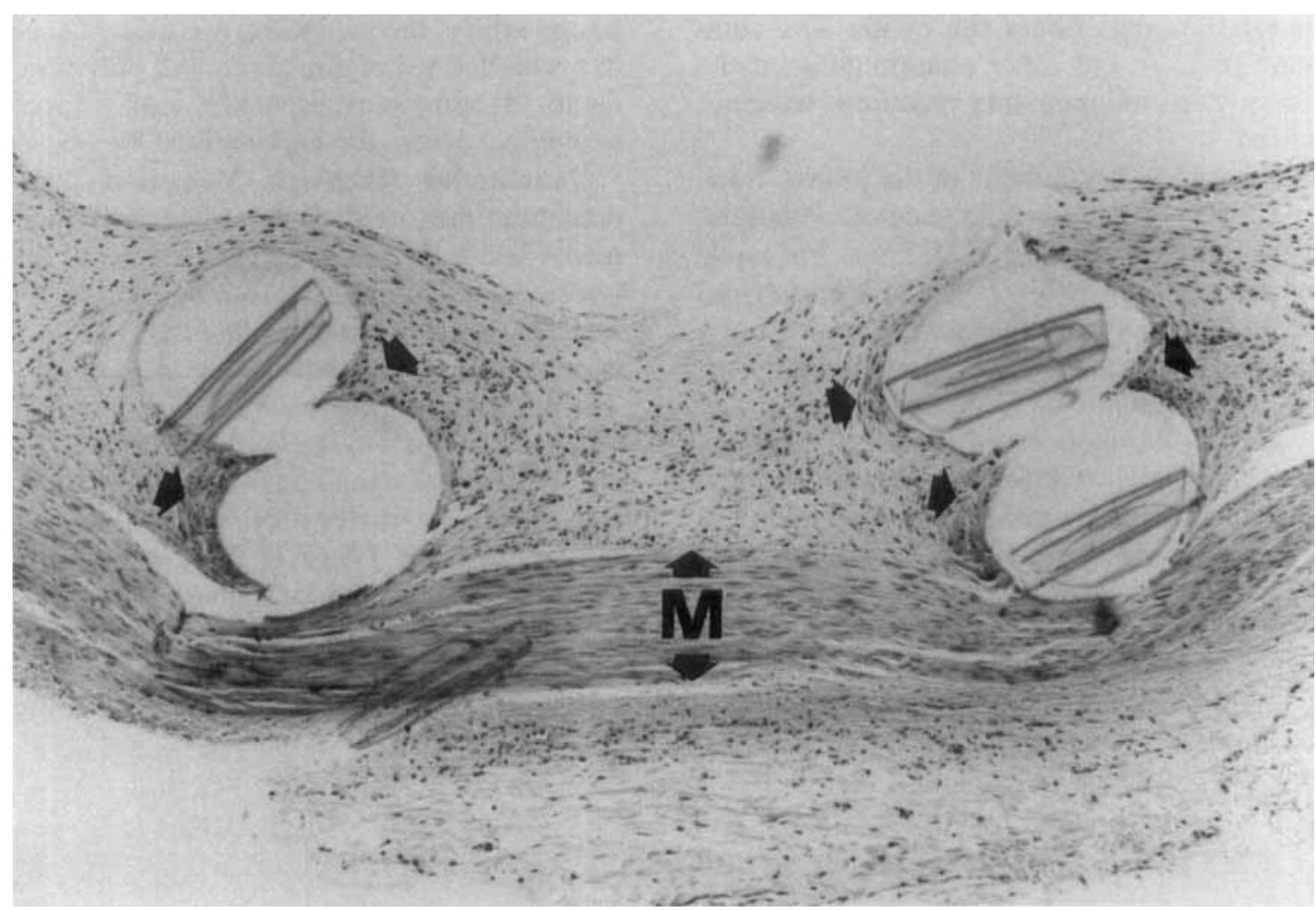

Figure 7. Photomicrograph of a porcine femoral artery 4 weeks after implantation of a polyester stent (magnification $100 \times$, hematoxylin-azofloxine stain). Note the limited compression of the media (M) under the fibers. The polymer material is still present. Around the polymer-occupied area a mild inflammatory reaction (arrows) can be observed.

weeks (Fig. 8A). The endothelial cells exhibited the typical immature, cobble stone aspect. Leucocytes and platelets were adherent to these patches of endothelium. In addition, large areas without a covering endothelial layer were observed (Fig. 8B).

\section{Discussion}

Choice of Polymer and Construction of Stent. Polyethylene-terephthalate is currently the most frequently used material for vascular grafts. It has considerable tensile strength and stiffness and is easy to handle for construction or design purposes. The uptake of water is $0.1 \%$ maximum, and does not influence mechanical behavior or glass transition temperature of the polymer, an important quality of a material intended for implantation in vivo. The glass transition tempera- ture of polyester (over $65^{\circ} \mathrm{C}$ ) is well outside from the physiological range. The mechanical properties of (drawn) polyester fibers can be varied within considerable limits depending on processing conditions.

In Vitro Pressure-Diameter Relationship and Hysteresis-Like Behavior. The results of the in vitro measurements confirm that the stiffness of the polyester stent construction is comparable to that of a stainless steel stent. A limitation of our study is that we did not measure the actual shortening of the device after prior elongation.

The mounting and release experiments, however, suggest hysteresis-like behavior that decreases this radial pressure of the polyester device at implantation. Partly, this hysteresis-like behavior originates in the braided construction and, partly, this is a feature of the polymer material itself. Since one of the most likely causes of extensive neointimal proliferation and restenosis 


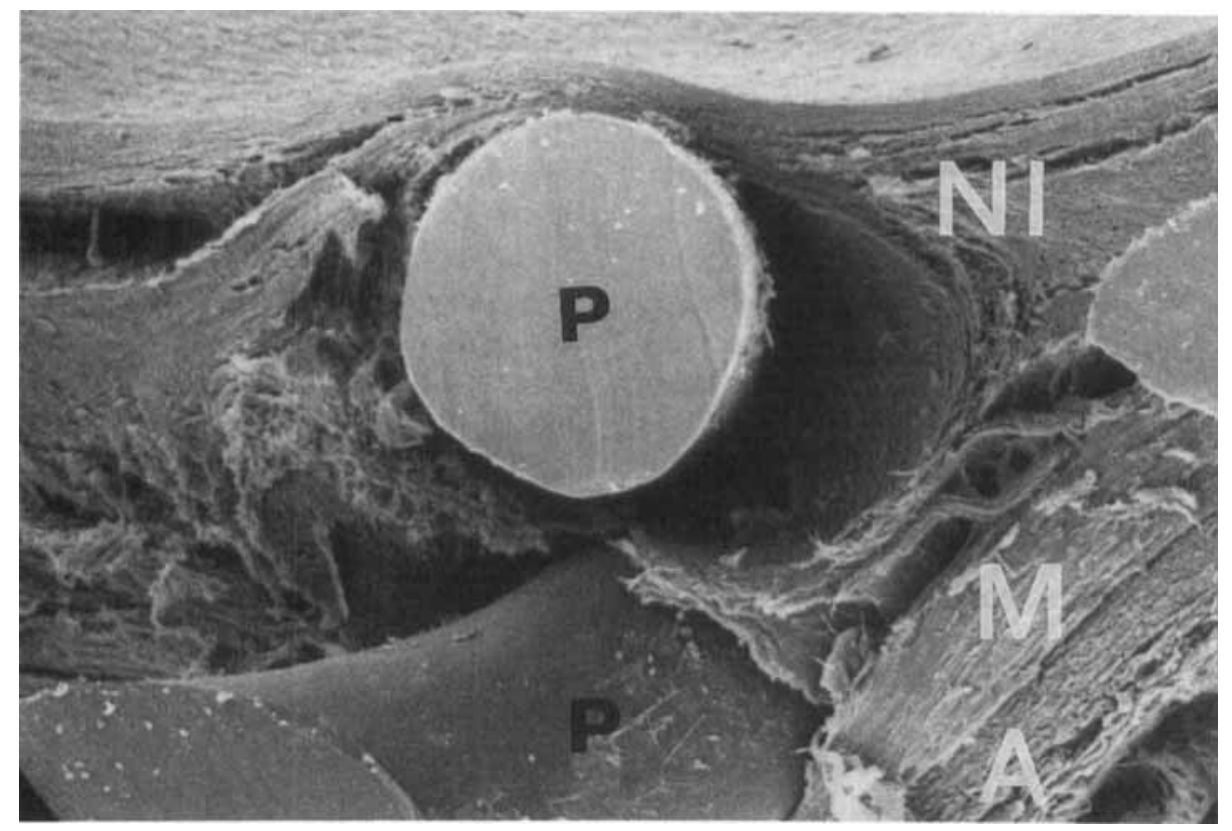

Figure 8A. Scanning electron microscopical picture of polymer stent fibers $(\mathrm{P})$ incorporated in the (cut surface of the) vessel wall at 4 weeks (magnification $150 \times$ ). NI = neointima; $\mathrm{M}=$ media; $\mathrm{A}$ $=$ adventitia.

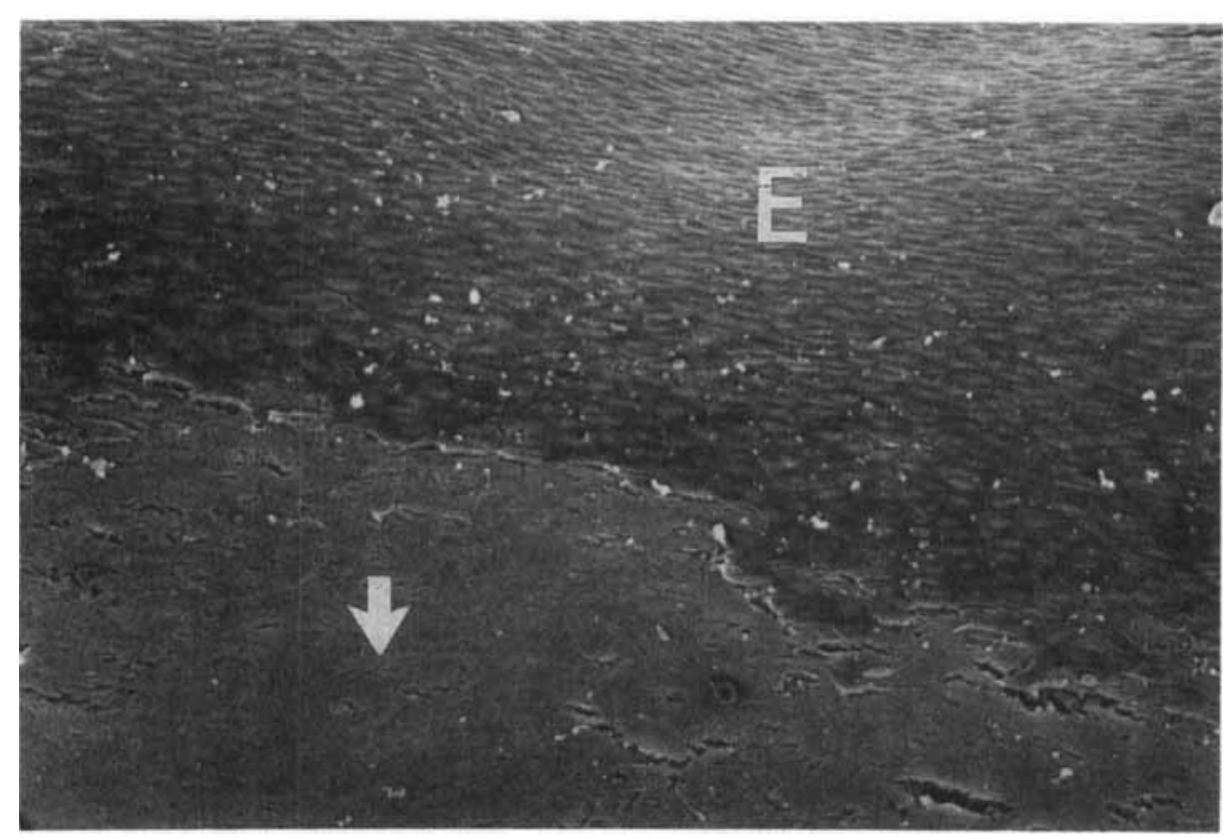

Figure 8B. The neointima of the stented segment is partly covered by patches of endothelium ( $E$; upper part of photograph), but not endothelialized at the lower part (arrow; magnification 150 $\times$ ). 
VAN DER GIESSEN, ET AL.

is the acute barotrauma to the vessel wall, ${ }^{29}$ the loss of radial pressure is probably not a disadvantage. The employment of polymer stents may reduce acute vessel wall damage because of a slower build up of radial pressure and, consequently, a softer settling of the polymer stent against the arterial wall. In fact, some polymer materials may be expected to simulate the stressstrain response of a blood vessel much closer than a metal would do. So, contrary to metallic, self-expanding stents, which are associated with an increased risk of restenosis when more than $0.7 \mathrm{~mm}$ oversized compared to the target vessel diameter, ${ }^{30}$ polymer stents need considerable oversizing ( $2 \mathrm{~mm}, 60 \%$ ) to effectively splint the artery.

In Vivo Implantations. Implantation of the polyester stents was uneventful, although two stents were eventually found in the aortic bifurcation, most likely due to the defective prototype delivery system. After 4 weeks, five of the six properly placed stents were patent with only limited neointimal proliferation. These results are considerably better than those reported for another polyester stent. ${ }^{31}$ The fact that, in the latter study, stents with an unconstrained diameter of only 3.0 $\mathrm{mm}$ (contrary to our stents of $5.3 \mathrm{~mm}$ ) were used in the coronary circulation may have been responsible for the $100 \%$ occlusion rate, most likely due to thrombosis, since polyester is able to activate platelets systemically. ${ }^{32}$

Angiography. Quantitative angiographic assessment showed no increase in luminal diameter after stenting (diameter change $-0.1 \pm 0.2 \mathrm{~mm}$, no oversizing). The fact that the arteries were not overstretched may have contributed to the high patency rate. In addition, the angiographic data verified that the considerable hysteresis-like behavior, which was found in vitro, also occurred in vivo. On the other hand, the stents proved firm enough to resist vasospasm, which is to some extent always present after the placement of stents in porcine arteries.

Histology and Electron Microscopy. Microscopical examination showed a limited amount of neointimal proliferation in the polyester stents. Considerable differences between the histologic appearance of the neointima were, nonetheless, observed in the present study as compared to the results obtained with metallic stents. An exten- sive inflammatory reaction surrounded all embedded fibers, in addition to polymer inclusions elsewhere in the neointima. The former observation is in agreement with that reported by others. ${ }^{31}$ In spite of this foreign body reaction, the thickness of the neointima was similar to that observed after implantation of metallic stents in the same species. ${ }^{21,26}$

Immediately before implantation, we sterilized the stents in a Cidex solution containing $2 \%$ glutaraldehyde, or chloorhexidine in alcohol for 15 min. Theoretically, polyester may absorb up to $10-100 \mathrm{ppm}$ of glutaraldehyde and up to $0.01 \%$ of alcohol during the immersion period. The inflammatory tissue reaction observed in our study may in part be aggravated by the local irritant effect of glutaraldehyde and/or alcohol-derived acetaldehyde after diffusion in the vessel wall. ${ }^{33}$ The experiments may, therefore, be regarded as being performed in a "worst case" environment.

In some arteries we observed signs of inflammatory cells invading the polyester fibers, or surrounding inclusions of polymer separate from the fibers, most likely due to damage to the fibers during the braiding process. This observation underscores the requirement for "gentle" production techniques for polymeric stents.

Polyester stents are biostable and permanent after incorporation in the arterial wall. A well known problem with permanent, polymer implants is their tendency for calcification. Bioresorbable stents, which are only temporary present, have been suggested as a more promising alternative ${ }^{34,35}$ It must be considered, however, that the breakdown process in itself may aggravate the inflammatory reaction, already present around nonresorbable polymer material.

The present study shows the feasibility of the arterial implantation of polyester stents, with good intermediate term results. The abundant inflammatory reaction, if prolonged and associated with local vascular dysfunction, could, however, limit the use of polyester stents in the coronary arterial tree of patients.

\section{References}

1. Anderson HV, Roubin GS, Leimgruber PP, et al. Primary angiographic success rates of percutaneous transluminally angioplasty. Am J Cardiol 1985; 56:712-717.

2. Myler RK, Topol EJ, Shaw RE, et al. Multiple vessel coronary angioplasty: Classification, results and pat- 


\section{POLYESTER STENTS IN PIGS}

terns of restenosis in 494 consecutive patients. Cathet Cardiovasc Diagn 1987; 13:1-15.

3. Bredlau CE, Roubin GS, Leimgruber PP, et al. In-hospital morbidity and mortality in patients undergoing elective coronary angioplasty. Circulation 1985; 72: 1044-1052.

4. Simpfendorfer C, Belardi J, Bellamy G, et al. Frequencies, management and follow-up of patients with acute coronary occlusion after percutaneous transluminal angioplasty. Am J Cardiol 1987; 59:267-269.

5. De Feyter PJ, Van den Brand M, Laarman GJ, et al. Acute coronary artery occlusion during and after percutaneous transluminal coronary angioplasty. Frequency, prediction, clinical course, management, and follow-up. Circulation 1991; 83:927-936.

6. Mufson L, Black A, Roubin G, et al. A randomized trial of aspirin in PTCA: Effect of high vs low dose aspirin on major complications and restenosis. (abstract) J Am Coll Cardiol 1988; 11:236A.

7. Lembo NJ, Black AJ, Roubin GS, et al. Does the addition of dipyridamole to aspirin decrease acute coronary angioplasty complications? The results of a prospective randomized clinical trial. (abstract) J Am Coll Cardiol 1988; 11:237A.

8. Chesebro JH, Webster MWl, Reeder GS, et al. Coronary angioplasty: Antiplatelet therapy reduces acute complications but not restenosis. (abstract) Circulation 1989; 80(Suppl. II):II-64.

9. Serruys PW, Luijten HE, Beatt KJ, et al. Incidence of restenosis after successful coronary angioplasty: A timerelated phenomenon. Circulation 1988; 77:361-371.

10. Nobuyoshi M, Kimura T, Nosaka H, et al. Restenosis after successful percutaneous transluminal coronary angioplasty: Serial angiographic follow-up of 299 patients. J Am Coll Cardiol 1988; 12:616-623.

11. Detre K, Holubkov R, Kelsey S, et al. Percutaneous transluminal coronary angioplasty in 1985-1986 and 1977-1981. N Engl J Med 1988; 318:265-270.

12. Blackshear JL, O'Callaghan WG, Califf RM. Medical approaches to prevention of restenosis after coronary angioplasty. J Am Coll Cardiol 1987; 9:834-848.

13. Popma JJ, Califf RM, Topol EJ. Clinical trials of restenosis after coronary angioplasty. Circulation 1991; 84: 1426-1436.

14. Hermans WRM, Rensing BJ, Strauss BH, et al. Prevention of restenosis after percutaneous transluminal coronary angioplasty: The search for a "magic bullet". Am Heart J 1991; 122:171-187.

15. Carrel A. Results of the permanent intubation of the thoracic aorta. Surg Gynecol Obstet 1912; 15:245-248.

16. Dotter CT. Transluminally-placed coilspring endarterial tube grafts. Long-term patency in the canine popliteal artery. Invest Radiol 1969; 4:329-332.

17. Sigwart U, Puel J, Mirkovitch V, et al. Intravascular stent to prevent occlusion and restenosis after transluminal angioplasty. N Engl J Med 1987; 316:701-706.

18. Serruys PW, Strauss BH, Beatt KJ, et al. Angiographic follow-up after placement of a self-expanding coronaryartery stent. N Engl J Med 1991; 324:13-17.

19. Schatz RA, Baim DS, Leon M, et al. Clinical experience with the Palmaz-Schatz coronary stent. Initial results of a multicenter study. Circulation 1991; 83:148-161.

20. Roubin GS, Hearn JA, Carlin SF, et al. Angiographic and clinical follow-up in patients receiving a balloon expandable, stainless steel, stent (Cook, Inc.) for preven- tion or treatment of acute closure after PTCA. (abstract) Circulation 1990; 82(4 Suppl. III):III-191.

21. Van der Giessen WJ, Serruys PW, Van Beusekom HMM, et al. Coronary stenting with a new, radiopaque, balloon-expandable endoprosthesis in pigs. Circulation 1991; 83:1788-1798.

22. De Jaegere PP, Serruys PW, Bertrand ME, et al. Wiktor stent implantation in patients with restenosis following balloon angioplasty of a native coronary artery. Am J Cardiol 1992; 69:598-602.

23. Reiber JHC, Kooijman CJ, Slager CJ, et al. Coronary artery dimensions from cineangiograms-methodology and validation of a computer-assisted analysis procedure. IEEE Trans Med Imaging 1984; MI-3:131-141.

24. Reiber JHC, Serruys PW, Kooijman CJ, et al. Assessment of short-, medium- and long-term variations in arterial dimensions from computer-assisted quantitation of coronary cineangiograms. Circulation 1985; 71:280-288.

25. Serruys PW, Reiber JHC, Wijns W, et al. Assessment of percutaneous transluminal coronary angioplasty by quantitative coronary angiography: Diameter versus densitometric area measurements. Am J Cardiol 1984; $54: 482-488$

26. Van der Giessen WJ, Serruys PW, Van Woerkens LJ, et al. Arterial stenting with self-expandable and balloonexpandable endoprostheses. Int J Card Imaging 1990; 5: 163-171.

27. Polimeni PI, Cunningham P, Otten MD, et al. Morphometric quantification of atherosclerotic plaques by computer-assisted image-analysis of histographs. Comput Biomed Res 1987; 20:113-124.

28. Weiner BH, Ockene JS, Jarmolych J, et al. Comparison of pathologic and angiographic findings in a porcine preparation of coronary atherosclerosis. Circulation $1985 ; 72: 1081-1086$

29. Schwartz RS, Murphy JG, Edwards WD, et al. Restenosis after balloon angioplasty: A practical proliferative model in porcine coronary arteries. Circulation 1990; 82 : 2190-2200.

30. Strauss BH, Serruys PW, de Scheerder IK, et al. Relative risk analysis of angiographic predictors of restenosis within the coronary Wallstent. Circulation 1991; 84: 1636-1643.

31. Murphy JG, Schwartz RS, Edwards WD, et al. Experimental coronary artery stenosis induced by polymer (PET) implantation in domestic swine. (abstract) J Am Coll Cardiol 1991; 17(6 Suppl. B): 195B.

32. Schoenfeld NA, Connolly R, Ramberg K, et al. The systemic activation of platelets by Dacron grafts. Surg Gynecol Obstet 1988; 166:454-457.

33. Ben Slimane S, Guidoin R, Marceau D, et al. Characteristics of polyester arterial grafts coated with albumin: The role and importance of the cross-linking chemicals. Eur Surg Res 1988; 20:18-28.

34. Zdrahala RJ, MacGregor DC, Clark HG, et al. Bioresorbable endovascular stent; Part I: Concept, feasibility, and material considerations. (abstract) Proceedings 8th Eur. Conference on Biomaterials, Heidelberg 7 th-9th September 1989, A6-4.

35. Chapman GD, Gammon RS, Bauman RP, et al. A bioabsorbable stent: Initial experimental results. (abstract) Circulation 1990; 82(Suppl. III):III-72.

36. Serruys PW, Strauss BH, van Beusekom HMM, et al. Stenting of coronary arteries. Has a modern Pandora's Box been opened? J Am Coll Cardiol 1991; 17(6 Suppl. B): 143B-154B 